Please do not remove this page

RMIT

UNIVERSITY

\title{
p38 MAP kinase mediated proteoglycan synthesis as a target for the prevention of atherosclerosis
}

Osman, Narin; Ballinger, Mandy; Dadlani, Harsha; Getachew, Robel; Burch, Micah; Little, Peter https://researchrepository.rmit.edu.au/esploro/outputs/9921857626901341/filesAndLinks?institution=61RMIT_INST\&index=null

Osman, N., Ballinger, M., Dadlani, H., Getachew, R., Burch, M., \& Little, P. (2008). p38 MAP kinase mediated proteoglycan synthesis as a target for the prevention of atherosclerosis. Cardiovascular and Haematological Disorders - Drug Targets, 8(4), 287-292. https://doi.org/10.2174/187152908786786205 Document Version: Accepted Manuscript

Published Version: https://doi.org/10.2174/187152908786786205

Repository homepage: https://researchrepository.rmit.edu.au (c) 2008 Bentham Science Publishers Ltd.

Downloaded On 2023/04/26 14:23:26 +1000 
Thank you for downloading this document from the RMIT Research Repository.

The RMIT Research Repository is an open access database showcasing the research outputs of RMIT University researchers.

RMIT Research Repository: http://researchbank.rmit.edu.au/

\section{Citation:}

Osman, N, Ballinger, M, Dadlani, H, Getachew, R, Burch, M and Little, P 2008, 'p38 MAP kinase mediated proteoglycan synthesis as a target for the prevention of atherosclerosis', Cardiovascular and Haematological Disorders - Drug Targets, vol. 8, no. 4, pp. 287-292.

See this record in the RMIT Research Repository at: http://researchbank.rmit.edu.au/view/rmit:23358

Version: Accepted Manuscript

Copyright Statement: (c) 2008 Bentham Science Publishers Ltd.

Link to Published Version:

http://dx.doi.org/10.2174/187152908786786205 


\section{p38 MAP kinase mediated proteoglycan synthesis as a target for the prevention of atherosclerosis.}

Narin Osman ${ }^{1,2^{*}}$, Mandy L. Ballinger ${ }^{1}$, Harsha M. Dadlani ${ }^{1}$, Robel Getachew ${ }^{1,3}$, R., Micah L. Burch $^{1,2}$ and Peter J. Little ${ }^{1-4}$.

${ }^{1}$ Diabetes and Cell Biology Laboratory, BakerIDI Heart and Diabetes Institute, Melbourne, Victoria, 3004, Australia and Departments of ${ }^{2}$ Immunology and ${ }^{4}$ Medicine, Central and Eastern Clinical School, Alfred Hospital, Monash University, Melbourne, Victoria, 3004, Australia, ${ }^{3}$ RMIT University, School of Medical Sciences, Bundoora, 3083 Victoria, Australia.

Address for correspondence:

A/Prof. Peter J. Little, Head, Diabetes and Cell Biology Laboratory BakerIDI Heart and Diabetes Institute Postal Address: $\quad$ St. Kilda Rd Central, PO Box 6492, Melbourne, VIC 8008, Australia Courier Address: $\quad 75$ Commercial Road, Melbourne, VIC 3004, Australia

Tel.: $\quad+61385321203$

Fax: $\quad+61385321100$

Email: peter.little@,baker.edu.au 
Abbreviations: MAP kinase, Mitogen Activated Protein kinase; PDGF, platelet derived growth factor; TGF, transforming growth factor; VSMC, Vascular smooth muscle cells; GAG, glycosaminoglycan; CS, chondroitin sulfate; DS, dermatan sulfate.

Page 2 


\begin{abstract}
The major underlying pathology of most cardiovascular disease is the chronic inflammatory disease of atherosclerosis. Type 2 diabetes, also recognised as an inflammatory condition, accelerates the development of atherosclerosis. Current therapies for atherosclerosis target risk factors such as elevated blood lipids and hypertension and are of strong but limited efficacy. The "response to retention" hypothesis states that atherosclerosis is initiated by the accumulation of lipids through binding to extracellular matrix, and this is specifically the glycosaminoglycan (GAG) chains on proteoglycans. Many vasoactive agonists stimulate changes in the structure of the GAGs which increase lipid binding and the relevant signalling pathways are a potential therapeutic target. It has recently been demonstrated that the actions of transforming growth factor $\beta$ on vascular smooth muscle proteoglycan synthesis involves signalling through p38 MAP kinase and inhibition of this pathway reduces binding of lipids. Inhibition of p38 MAP kinase will elicit a wide spread antiinflammatory response which may alleviate some of the deleterious processes in cardiovascular tissues. This article explores the potential for the actions of p38 MAP kinase inhibitors directed at proteoglycan synthesis in vascular smooth muscle to contribute to the beneficial outcomes from targeting p38 MAP kinase for the prevention of cardiovascular disease.
\end{abstract}

Keywords p38 MAP kinase, vascular smooth muscle, proteoglycans, glycosaminoglycans, atherosclerosis 


\section{Introduction}

Cardiovascular disease is the largest cause of mortality in modern society. Atherosclerosis and the rupture of atherosclerotic plaques is the major underlying pathology [1-3]. Atherosclerosis is accelerated by the hyperglycaemic milieu of diabetes rendering cardiovascular disease the cause of death for the majority of people with diabetes [4]. Major preventative treatments are targeted at epidemiologically-identified and clinically validated risk factors such as hyperlipidemia and hypertension. Treatment with the statin class of lipid lowering agents has been the mainstay of treatment for the last two decades but this approach has a limited efficacy of about 30 percent prevention and two thirds of statin treated patients experience adverse cardiovascular events [5]. Recent efforts have explored new risk factors particularly systemic factors related to inflammation $[1,6,7]$. Inflammation, the involvement of cells of the immune system and their associated cytokines, has become very widely part of the paradigm of chronic disease including diabetes and atherosclerosis. However, the question has been raised of the primary or secondary nature of inflammation [8] and the issue remains as to how the beneficial aspects of immune function can be separated from the role in chronic disease? [8]. Compared to risk factor directed strategies a more complex but potentially more rewarding approach might be to target earlier aspects of the disease process in the vessel wall [9]. Such an approach might target the inflammatory aspects of plaque formation but recent strong evidence has pointed to the secondary nature of inflammation in the early stages of human atherosclerosis [10]. The initiating event in atherosclerosis has been identified as the trapping of atherogenic lipoproteins by extracellular matrix molecules, particularly the proteoglycan biglycan $[10,11]$ and biglycan with modified GAG chains has been proposed as the specific initiating factor 
[12]. This step has been enunciated by of Williams and Tabas as the "response to retention" hypothesis $[13,14]$. Although much of the focus of the response to retention hypothesis has been from the perspective of lipid involvement [8], we are evaluating the potential of targeting the proteoglycan components and their role [9, 15]. Lipoproteins bind to the GAG chains of chondroitin/dermatan (CS/DS) sulfate proteoglycan, particularly biglycan. Elongated GAG chains have been identified in the vessel wall of an animal model of atherosclerosis [16]. Considerable in vitro data has demonstrated that GAG chains are modified by various vasoactive agents and metabolic factors that induce structural changes to increase the stickiness for lipoproteins [17-19]. Pharmacological tools, receptor antagonists and cardiovascular and diabetes drugs can also prevent these atherogenic structural changes in GAGs in in vitro models [20-23]. We propose that targeting the regulatory signalling pathways, and not the synthetic enzymes, per se, through which GAG chains on proteoglycans in the vessel wall are modified in atherosclerosis represents a target worthy of full evaluation for its potential to prevent or delay the initiation of atherosclerosis [9].

The signalling family known as Mitogen Activated Protein (MAP) kinases has lately become of increasing prominence in studies of cellular functions related to cardiovascular disease. MAP kinases include most prominently, ERK1/2, JNK and p38 $[24,25]$. ERK has been implicated in cell growth responses [26] whereas the later two entities were initially implicated in stress related cell signalling involving inflammatory cytokines and apoptosis $[27,28]$. More recently JNK and p38 MAP kinases are being seen as part of main stream signalling for a variety of pathways in vascular smooth muscle cells. p38 MAP kinases regulate the expression of many cytokines. They are in turn activated by many inflammatory cytokines thus playing an important role in 
immune responses and these include those associated with chromic inflammation such as diabetes and atherosclerosis. The role of p38 MAP kinase in inflammation also invokes a role for inhibitors in reducing the chronic inflammatory state of diabetes and thus a reduction in cardiovascular disease risk from a lowering of the impact of insulin resistance and the metabolic syndrome on the accelerated development of atherosclerosis [29]. Simply, the beneficial actions of p38 inhibitors on metabolism may complement direct actions on the cells of the cardiovascular system.

Cell surface tyrosine kinase receptors such as platelet-derived growth factor (PDGF), the major serine/threonine kinase cell surface receptor, Transforming Growth Factor (TGF) $\beta$ receptor as well as 7 transmembrane $G$ protein coupled receptors (angiotensin II and endothelin receptors) have recently been found to target intermediates that lead to the phosphorylation and activation of MAP kinases including p38 MAP kinase [28, 30-32]. Furthermore, although the TGF $\beta$ Type I receptor, ALK V, has been shown to mediate effects on proteoglycan metabolism of vascular smooth muscle cells via the canonical Smad pathway(s) [33], the MAP kinase, p38, can also mediate the effects of ALK V on GAG elongation in human vascular smooth muscle cells [34]. TGF $\beta$ is strongly implicated in atherosclerosis and this action alone may be pivotal $[17,35]$. However, many other signalling pathways for vasoactive agents may invoke p38 MAP kinase signalling and thus p38 MAP kinase may represent a critical and common point in the machinery of GAG synthesis. Because atherosclerosis is associated with growth factor cascades involving at least multiple protein kinase as well as 7 transmembrane $\mathrm{G}$ protein coupled receptor agonists it will be necessary to identify a common signalling target which will allow for targeted therapy to prevent 
modifications of GAGs and proteoglycans in the vessel wall and diminish lipid binding and the development of atherosclerosis.

In this review we assess the potential of p38 MAP kinase as a target for the prevention of atherosclerosis and cardiovascular disease and with a specific focus on the role of proteoglycans in initiating atherosclerosis as a therapeutic target.

\section{Properties of p38 MAP kinases}

p38 MAP kinase occurs as four isoforms $\alpha$ (gene name MAPK14), $\beta$ (MAPK11), $\delta$ (MAPK13) and $\gamma$ (MAPK12). The $\alpha$ isoform is the most widely studied and is expressed in most cells. p38 MAP kinase activity was originally defined in a screen of antiinflammatory drugs in the early 1990s [36] and was later found as a tyrosine phosphorylated protein in macrophages $[24,37]$. Although the multiple isoforms share about 40 per cent homology with other MAP kinases they only share 60 per cent identity with one another [38]. The kinases respond to a large number of extracellular stimuli including UV radiation, osmotic shock and hypoxia. It was originally considered to have limited involvement in growth factor responses but emerging data of its role in multiple growth factor regulated cellular responses questions this delineation. p38 MAP kinase is activated by dual (tyrosine and threonine) phosphorylation on the Thr-Gly-Tyr (TGY) (threonine 180 and tyrosine 182) motif in its activation loop. Activation occurs through the action of the upstream protein kinases, MEK3 and -6 [38] see Fig. (1).

The action of p38 MAP kinase in cell functions is determined by upstream activators and modulators and downstream effectors. It exists as a component of a linear trio of cascading kinases and is subject to the regulatory control common to the MAP kinase family. The cascade covering all MAP kinases commences with the MAPKKK 
(of which there are more than 20), downstream to MAPKK (7 members) and concludes with MAP kinase of which there are about 11 . MAPKKK can selectively control the localisation, activation and inactivation of MAPKKs and thus MAP kinases. MAPKKKs can phosphorylate and activate more than one class of MAPKK thus leading to coordinated activation of multiple MAP kinases and thus the potential number of subtle variations in signal transduction emphasis is enormous. The upstream activators and downstream effectors of p38 MAP kinase are shown in Fig. (1). In addition, scaffolding proteins play a substantial role in the modulation of signal transduction and in a recent development it has been shown that the p38 $\alpha$ isoform is activated by TAB1 [39] which is not a MEKK, opening a further area for considering the regulation and activation of this and potentially other MAP kinases.

The trio of kinases provides multiple opportunities for pharmacological inhibition of the p38 MAP kinase cascade. Broadly, in this cascade inhibitors can inhibit the phosphorylation and activation of the upstream mediator (MAPKKK or MAPKK), inhibit the kinase activity of the upstream mediator and similarly inhibit either the phosphorylation or activation of a MAP kinase or directly its kinase activity, the last mentioned usually through competition with ATP. Other inhibitors can bind to inactive states of the kinases and inhibit activity by that mechanism. The different modes of action are observed most clearly when undertaking signalling studies by Western blotting. An inhibitor of an upstream kinase will reduce the appearance of the phospho MAP kinase target whereas an inhibitor such as SB202190 which binds to and inhibits the activity of phospho-p38 MAP kinase leads to an accumulation and increase in the observed level of phospho-p38 MAP kinase albeit that its activity in an intact cell would be inhibited. The development of inhibitors for p38 MAP kinase has been an area of 
considerable activity [40] and good inhibitors of p38 MAP kinase activity in cell based systems have been described [41]. The $\alpha$ and $\beta$ isoforms are inhibited by the imidazole derivatives such as SB202190 whereas the $\delta$ and $\gamma$ isoforms are insensitive to these compounds [41, 42]. Understandably, the availability of inhibitors has advanced the study of these two isoforms.

\section{Proteoglycans and atherosclerosis}

It has long been known that atherosclerosis commences with the accumulation of lipid in the vessel wall. It has been less appreciated that lipid accumulation occurs due to the binding of lipid mediators to proteoglycans in a step recognised in the mid 1990s as the response to retention hypothesis of Williams and Tabas $[13,14]$ and this has been updated and reaffirmed in recent reviews $[8,43]$. The implicated matrix molecules are the CS and DS proteoglycans, versican, biglycan and decorin. These CS/DS proteoglycans are less well known in vascular biology compared to the heparan sulfate proteoglycans long known for their role in regulating Fibroblast Growth Factor activity [44]. Areas of vessels that permit the development of atherosclerosis are enriched in proteoglycans, particularly the small dermatan sulfate proteoglycans, decorin and biglycan [11]. Decorin binds and inactivates transforming growth factor (TGF) $\beta$ which may be an anti-atherogenic action [45]. Biglycan is closely associated with lipid retention and the development of atherosclerosis $[10,46]$ and we have proposed that the form of biglycan with elongated GAG chains, termed "hyperelongated biglycan" is the initiating factor in atherosclerosis [12]. Apolipoproteins bind to the GAG chains on proteoglycans and binding is enhanced when the GAG chains are elongated or have an altered sulfation pattern that favours 6-sulfation of the GalNAc residues [15]. Vascular 
smooth muscle cells are the major source of proteoglycans in the vessel wall and accordingly modifications of GAG chain synthesis, particularly on biglycan, that increase binding of proteoglycans to lipoproteins is hypothesised to be a critical initiating event in atherosclerosis and hence a drug target $[9,15]$.

Experimental support for the contention that the initiating step of atherosclerosis is the sub-endothelial retention of lipoproteins by proteoglycans has been provided in several studies with animal models having genetically modified apolipoproteins (positively charged amino acid residues mutated to negative or neutral) where those that do not bind to proteoglycans do not precipitate atherosclerosis [16, 47]. Critically, a very recent human pathology study microscopically examined the earliest stages of human coronary artery disease, before eruptive atherosclerosis was present. The early events occur in areas of diffuse intimal thickening, and lipid accumulation occurs before significant macrophage penetration and foam cell formation [10]. The early lipid accumulates extracellularly, instead of passing through the vessel wall and into the interstitial fluid [48]. The early accumulated lipid occurs in association with the proteoglycans, biglycan and decorin, but most closely with biglycan distribution [10].

\section{p38 MAPK signalling and proteoglycan synthesis}

p38 MAPK is known to be involved in a number of signalling cascades that result in altered extracellular matrix and proteoglycan synthesis. In the pancreatic carcinoma cell line PANC-1 TGF- $\beta$ stimulation leads to p38 MAPK activation and induction of the CS/DS proteoglycan biglycan expression via transcriptional induction

of growth arrest DNA damage $45 \beta$ (GADD45 $\beta$ ) $[49,50]$. In this case both p38 MAPK activation and biglycan expression are dependent on adhesion and activation of the 
small Rho family GTPase Rac1 [51]. Heparan sulfate proteoglycan betaglycan in the absence of TGF- $\beta$ in myoblasts also signals via p38 MAPK and is independent of ERK signalling [52]. p38 MAPK regulates TGF- $\beta$ mediated expression of xylosyltransferase I [53] a key initiating and rate-limiting enzyme in GAG biosynthesis. Our own work has clearly demonstrated an involvement of p38 MAPK in TGF- $\beta$-mediated GAG synthesis in human vascular smooth muscle cells. p38 MAP kinase inhibitors SB203580 and SB202190 blocked vascular smooth muscle cells GAG synthesis in a concentrationdependent manner [34]. p38 is activated in vascular smooth muscle cells by agonists involved in atherosclerosis including thrombin, PDGF, angiotensin and endothelin see Fig. (2). While these agonists activate p38 MAPK to exert effects on growth, migration, inflammation, glucose metabolism and extracellular matrix the involvement of p38 MAPK in their actions on proteoglycan synthesis is still to be explored.

\section{Diabetes, atherosclerosis and p38 MAPK signalling}

Inhibition of the p38 MAPK signalling pathway in TGF $\beta$-mediated GAG elongation significantly reduces LDL binding by proteoglycans in human vascular smooth muscle cells [34]. The impact of this inhibition implies a potential role for $\mathrm{p} 38$ MAPK in the early stages of atherosclerosis. Indeed p38 MAPK is known to be involved in a number of other vascular smooth muscle cells signalling cascades that may contribute to the development of atherosclerosis and in the case of diabetes exacerbate the progression of the disease. Interestingly glucose mediates significant effects on p38 MAPK signalling in vascular smooth muscle cells. p38 MAPK signalling is activated in rat vascular smooth muscle cells cultured in $>16.5 \mathrm{mmol} / \mathrm{L}$ glucose $[54$, 55] and in aortic SMCs of streptozotocin-induced diabetic rats [30]. At this moderate 
level of glucose $(<16.5 \mathrm{mmol} / \mathrm{L})$ p38 MAPK is activated via a PKC- $\delta$ isoformdependent pathway whereas at $22 \mathrm{mmol} / \mathrm{L}$ glucose activation is osmotically mediated and PKC-independent [54]. In human endothelial cells high glucose $(25 \mathrm{mM})$ increases p38 MAPK activity and mediates an antiproliferative growth response via TGF $\beta$ however induction of cellular hypertrophy is independent of p38 MAPK [56]. In vascular smooth muscle cells high glucose significantly increases expression and phosphorylation of p38 MAPK protein however these changes do not have a role in glucose-potentiated chemotaxis [55]. In diabetic rat vascular smooth muscle cells PDGF stimulates p38 MAPK phosphorylation and is mediated by $\mathrm{PKC}-\delta$ and subsequent MKK3/6 activity regulating cell growth, migration, COX-2 expression and arachidonic acid release, significant inflammatory mediators [30]. In rat vascular smooth muscle cells p38 MAPK mediates thrombin induced glucose uptake via the tyrosine kinase src [57]. Thus it is clear that p38 MAPK is centrally involved in a number of vascular smooth muscle cells signalling cascades and that p38 MAPK activity is significantly increased in the presence of hyperglycemia or diabetes. However, there are alternative p38 MAPK activation pathways other than the MAPK cascade and it is likely that the tissue-specific and agonist restricted pathway intermediates provide the potential for selective targeting in the prevention of atherosclerosis.

\section{Conclusion}

In terms of GAG synthesis and structure as a target for the prevention of atherosclerosis the ideal scenario would be for the identification of a single target associated specifically with modifications of GAG chain synthesis and structure that are 
associated with increased lipid binding [9, 15]. p38 MAP kinase has recently been identified as one such target and further work is required to define the role of this kinase in the signalling pathways of other vasoactive agonists $[9,15]$.

In addition to the vascular actions described above, p38 MAP kinase is involved in a wide variety of pathways associated with insulin resistance and thus diabetes and also with aspects of cardiovascular disease so it is an intriguing drug target $[36,40,58]$. In this context one might relate the potential of p38 MAP kinase inhibitors to that of Peroxisome Proliferating Activating Receptor (PPAR) ligands [59] and cannabinoid receptor antagonists [60] where these agents are also involved in multiple aspects of insulin resistance, obesity and cardiovascular disease and have multiple direct actions on vascular cells. If the molecular mechanisms which underlie the metabolic syndrome and exacerbate cardiovascular disease can be targeted with a single drug then the upside of identifying a molecule which has a broad spread of actions to simultaneously improve insulin resistance, reduce obesity and ameliorate cardiovascular disease is immense. Under these circumstances inhibition of GAG synthesis on proteoglycans might be one small but important component of the broad actions of p38 MAP kinase inhibition. p38 MAP kinase inhibitors certainly warrant full evaluation in the clinical setting for their ability to ameliorate the impending obesity-driven surge cardiovascular disease and its underlying aetiology of atherosclerosis. 
Declaration of Interest: The authors report no conflicts of interest. The authors alone are responsible for the content and writing of the paper.

Acknowledgements: The experimental work underpinning this review has been supported by National Health and Medical Research Council of Australia Project Grants, project grants from the Diabetes Australia Research Trust and a Grant-in-Aid from the National Heart Foundation of Australia. We are very grateful for the financial support provided by Mr. Beresford King to the BakerIDI Heart and Diabetes Institute in support of the seminal project related to this work. 


\section{References}

[1] Ross R. Atherosclerosis--an inflammatory disease. N Engl J Med 1999,340,(2):115-26.

[2] Davies MJ. Stability and instability: two faces of coronary atherosclerosis. The Paul Dudley White Lecture 1995. Circulation 1996,94,(8):2013-20.

[3] Falk E. Morphologic features of unstable atherothrombotic plaques underlying acute coronary syndromes. Am J Cardiol 1989,63,(10):114E-120E.

[4] Haffner SM, D'Agostino R, Jr., Mykkanen L, Tracy R, Howard B, Rewers M, Selby J, Savage PJ, Saad MF. Insulin sensitivity in subjects with type 2 diabetes. Relationship to cardiovascular risk factors: the Insulin Resistance Atherosclerosis Study. Diabetes Care 1999,22,(4):562-8.

[5] Pignone M, Phillips C, Mulrow C. Use of lipid lowering drugs for primary prevention of coronary heart disease: meta-analysis of randomised trials. Bmj 2000,321,(7267):983-6.

[6] Plutzky J. Inflammatory pathways in atherosclerosis and acute coronary syndromes. Am J Cardiol 2001,88,(8A):10K-15K.

[7] Libby P. Inflammation in atherosclerosis. Nature 2002,420,(6917):868-74.

[8] Tabas I, Williams KJ, Boren J. Subendothelial lipoprotein retention as the initiating process in atherosclerosis: update and therapeutic implications. Circulation 2007,116,(16):1832-44.

[9] Little PJ, Ballinger ML, Osman N. Vascular wall proteoglycan synthesis and structure as a target for the prevention of atherosclerosis. Vascular Health Risk Management 2007,3:1-8.

[10] Nakashima Y, Fujii H, Sumiyoshi S, Wight TN, Sueishi K. Early human atherosclerosis: accumulation of lipid and proteoglycans in intimal thickenings followed by macrophage infiltration. Arterioscler Thromb Vasc Biol 2007,27,(5):1159-65.

[11] O'Brien KD, Olin KL, Alpers CE, Chiu W, Ferguson M, Hudkins K, Wight TN, Chait A. Comparison of apolipoprotein and proteoglycan deposits in human coronary atherosclerotic plaques: colocalization of biglycan with apolipoproteins. Circulation 1998,98,(6):519-27.

[12] Little PJ, Osman N, O'Brien KD. Hyperelongated biglycan: the surreptitious initiator of atherosclerosis. Current Opinion in Lipidology 2008, 19:448-454.

[13] Williams KJ, Tabas I. The response-to-retention hypothesis of early atherogenesis. Arterioscler Thromb Vasc Biol 1995,15,(5):551-61.

[14] Williams KJ, Tabas I. The response-to-retention hypothesis of atherogenesis reinforced. Curr Opin Lipidol 1998,9,(5):471-4.

[15] Ballinger ML, Nigro J, Frontanilla KV, Dart AM, Little PJ. Regulation of glycosaminoglycan structure and atherogenesis. Cell Mol Life Sci 2004,61,(11):1296-306.

[16] Gustafsson M, Levin M, Skalen K, Perman J, Friden V, Jirholt P, Olofsson SO, Fazio S, Linton MF, Semenkovich CF, Olivecrona G, Boren J. Retention of lowdensity lipoprotein in atherosclerotic lesions of the mouse: evidence for a role of lipoprotein lipase. Circ Res 2007,101,(8):777-83. 
[17] Little PJ, Tannock L, Olin KL, Chait A, Wight TN. Proteoglycans synthesized by arterial smooth muscle cells in the presence of transforming growth factorbeta1 exhibit increased binding to LDLs. Arterioscler Thromb Vasc Biol 2002,22,(1):55-60.

[18] Figueroa JE, Vijayagopal P. Angiotensin II stimulates synthesis of vascular smooth muscle cell proteoglycans with enhanced low density lipoprotein binding properties. Atherosclerosis 2002,162,(2):261-268.

[19] Chang MY, Potter-Perigo S, Tsoi C, Chait A, Wight TN. Oxidized low density lipoproteins regulate synthesis of monkey aortic smooth muscle cell proteoglycans that have enhanced native low density lipoprotein binding properties. J Biol Chem 2000,275,(7):4766-73.

[20] Tannock LR, Little PJ, Barrett HB, Wight TN, Chait A. Versican synthesized in the presence of troglitazone is smaller and has reduced LDL binding. Art Throm Vasc Biol 2002,Abstract (in press).

[21] Nigro J, Ballinger M, Dilley R, Jennings G, Wight T, Little P. Fenofibrate modifies human vascular smooth muscle proteoglycans and reduces LDL binding. Diabetologia 2004,47:2105-13.

[22] Survase S, Ivey ME, Nigro J, Osman N, Little PJ. Actions of calcium channel blockers on vascular proteoglycan synthesis: relationship to atherosclerosis. Vascular Health and Risk Management 2005,1,(3):199-208.

[23] Little PJ, Osman N, de Dios ST, Cemerlang N, Ballinger M, Nigro J. Antiproliferative activity of oral anti hyperglycemic agents on human vascular smooth muscle cells: thiazolidinediones (glitazones) have enhanced activity under high glucose conditions. Cardiovasc Diabetol 2007,6,(1):33.

[24] Johnson GL, Lapadat R. Mitogen-activated protein kinase pathways mediated by ERK, JNK, and p38 protein kinases. Science 2002,298,(5600):1911-2.

[25] Bouallegue A, Daou GB, Srivastava AK. Endothelin-1-induced signaling pathways in vascular smooth muscle cells. Curr Vasc Pharmacol 2007,5,(1):4552.

[26] Kamimura M, Bea F, Akizawa T, Katus HA, Kreuzer J, Viedt C. Plateletderived growth factor induces tissue factor expression in vascular smooth muscle cells via activation of Egr-1. Hypertension 2004,44,(6):944-51.

[27] Zhou L, Opalinska J, Verma A. p38 MAP kinase regulates stem cell apoptosis in human hematopoietic failure. Cell Cycle 2007,6,(5):534-7.

[28] Yogi A, Callera GE, Montezano AC, Aranha AB, Tostes RC, Schiffrin EL, Touyz RM. Endothelin-1, but not Ang II, Activates MAP Kinases Through cSrc-Independent Ras-Raf-Dependent Pathways in Vascular Smooth Muscle Cells. Arterioscler Thromb Vasc Biol 2007.

[29] Nigro J, Osman N, Dart AM, Little PJ. Insulin Resistance and Atherosclerosis. Endocr Rev 2006,27,(3):242-259.

[30] Yamaguchi H, Igarashi M, Hirata A, Sugae N, Tsuchiya H, Jimbu Y, Tominaga M, Kato T. Altered PDGF-BB-induced p38 MAP kinase activation in diabetic vascular smooth muscle cells: roles of protein kinase C-delta. Arterioscler Thromb Vasc Biol 2004,24,(11):2095-101.

[31] McGillicuddy FC, O'Toole D, Hickey JA, Gallagher WM, Dawson KA, Keenan AK. TGF-beta1-induced thrombospondin-1 expression through the p38 MAPK pathway is abolished by fluvastatin in human coronary artery smooth muscle cells. Vascul Pharmacol 2006,44,(6):469-75. 
[32] Kusuhara M, Takahashi E, Peterson TE, Abe J, Ishida M, Han J, Ulevitch R, Berk BC. p38 Kinase is a Negative Regulator of Angiotensin II Signal Transduction in Vascular Smooth Muscle Cells: Effects on Na+/H+ Exchange and ERK1/2. Circulation Research 1998,83:824-831.

[33] Massague J, Seoane J, Wotton D. Smad transcription factors. Genes Dev 2005,19,(23):2783-810.

[34] Dadlani H, Ballinger ML, Osman N, Getachew R, Little PJ. Smad and p38 MAP kinase-mediated signaling of proteoglycan synthesis in vascular smooth muscle. $J$ Biol Chem 2008,283,(12):7844-52.

[35] Bobik A, Agrotis A, Kanellakis P, Dilley R, Krushinsky A, Smirnov V, Tararak E, Condron M, Kostolias G. Distinct patterns of transforming growth factor-beta isoform and receptor expression in human atherosclerotic lesions. Colocalization implicates TGF-beta in fibrofatty lesion development. Circulation 1999,99,(22):2883-91.

[36] Lee JC, Laydon JT, McDonnell PC, Gallagher TF, Kumar S, Green D, McNulty D, Blumenthal MJ, Heys JR, Landvatter SW, Strickler JE, McLaughlin MM, Siemens IR, Fisher SM, Livi GP, White JR, Adams JL, Young PR. A protein kinase involved in the regulation of inflammatory cytokine biosynthesis. Nature 1994,372,(6508):739-46.

[37] Chen Z, Gibson TB, Robinson F, Silvestro L, Pearson G, Xu B, Wright A, Vanderbilt C, Cobb MH. MAP kinases. Chem Rev 2001,101,(8):2449-76.

[38] Raman M, Chen W, Cobb MH. Differential regulation and properties of MAPKs. Oncogene 2007,26,(22):3100-12.

[39] Ge B, Gram H, Di Padova F, Huang B, New L, Ulevitch RJ, Luo Y, Han J. MAPKK-independent activation of p38alpha mediated by TAB1-dependent autophosphorylation of p38alpha. Science 2002,295,(5558):1291-4.

[40] Regan J, Breitfelder S, Cirillo P, Gilmore T, Graham AG, Hickey E, Klaus B, Madwed J, Moriak M, Moss N, Pargellis C, Pav S, Proto A, Swinamer A, Tong L, Torcellini C. Pyrazole urea-based inhibitors of p38 MAP kinase: from lead compound to clinical candidate. J Med Chem 2002,45,(14):2994-3008.

[41] Davies SP, Reddy H, Caivano M, Cohen P. Specificity and mechanism of action of some commonly used protein kinase inhibitors. Biochem $J \mathbf{2 0 0 0}, 351$, (Pt 1):95-105.

[42] Jiang Y, Chen C, Li Z, Guo W, Gegner JA, Lin S, Han J. Characterization of the structure and function of a new mitogen-activated protein kinase (p38beta). $J$ Biol Chem 1996,271,(30):17920-6.

[43] Nakashima Y, Wight TN, Sueishi K. Early atherosclerosis in humans: role of diffuse intimal thickening and extracellular matrix proteoglycans. Cardiovasc Res 2008,79,(1):14-23.

[44] Pye DA, Vives RR, Turnbull JE, Hyde P, Gallagher JT. Heparan sulfate oligosaccharides require 6-O-sulfation for promotion of basic fibroblast growth factor mitogenic activity. $J$ Biol Chem 1998,273,(36):22936-42.

[45] Evanko SP, Raines EW, Ross R, Gold LI, Wight TN. Proteoglycan distribution in lesions of atherosclerosis depends on lesion severity, structural characteristics, and the proximity of platelet-derived growth factor and transforming growth factor-beta. Am J Pathol 1998,152,(2):533-46. 
[46] O'Brien KD, Gordon D, Deeb S, Ferguson M, Chait A. Lipoprotein lipase is synthesized by macrophage-derived foam cells in human coronary atherosclerotic plaques. J Clin Invest 1992,89,(5):1544-50.

[47] Skalen K, Gustafsson M, Rydberg EK, Hulten LM, Wiklund O, Innerarity TL, Boren J. Subendothelial retention of atherogenic lipoproteins in early atherosclerosis. Nature 2002,417,(6890):750-4.

[48] Reichl D, Rudra DN, Myant NB, Pflug JJ. Further evidence for the role of high density lipoprotein in the removal of tissue cholesterol in vivo. Atherosclerosis 1982,44,(1):73-84.

[49] Ungefroren H, Lenschow W, Chen WB, Faendrich F, Kalthoff H. Regulation of biglycan gene expression by transforming growth factor-beta requires MKK6p38 mitogen-activated protein Kinase signaling downstream of Smad signaling. $J$ Biol Chem 2003,278,(13):11041-9.

[50] Ungefroren H, Groth S, Ruhnke M, Kalthoff H, Fandrich F. Transforming growth factor-beta (TGF-beta) type I receptor/ALK5-dependent activation of the GADD45beta gene mediates the induction of biglycan expression by TGF-beta. J Biol Chem 2005,280,(4):2644-52.

[51] Groth S, Schulze M, Kalthoff H, Fandrich F, Ungefroren H. Adhesion and Rac1dependent regulation of biglycan gene expression by transforming growth factor-beta. Evidence for oxidative signaling through NADPH oxidase. J Biol Chem 2005,280,(39):33190-9.

[52] Santander C, Brandan E. Betaglycan induces TGF-beta signaling in a ligandindependent manner, through activation of the p38 pathway. Cell Signal 2006,18,(9):1482-91.

[53] Prante C, Milting H, Kassner A, Farr M, Ambrosius M, Schon S, Seidler DG, Banayosy AE, Korfer R, Kuhn J, Kleesiek K, Gotting C. Transforming Growth Factor beta1-regulated Xylosyltransferase I Activity in Human Cardiac Fibroblasts and Its Impact for Myocardial Remodeling. J Biol Chem 2007,282,(36):26441-9.

[54] Igarashi M, Wakasaki H, Takahara N, Ishii H, Jiang ZY, Yamauchi T, Kuboki K, Meier M, Rhodes CJ, King GL. Glucose or diabetes activates p38 mitogenactivated protein kinase via different pathways. J Clin Invest 1999,103,(2):18595.

[55] Campbell M, Allen WE, Sawyer C, Vanhaesebroeck B, Trimble ER. Glucosepotentiated chemotaxis in human vascular smooth muscle is dependent on crosstalk between the PI3K and MAPK signaling pathways. Circ Res 2004,95,(4):380-8.

[56] McGinn S, Saad S, Poronnik P, Pollock CA. High glucose-mediated effects on endothelial cell proliferation occur via p38 MAP kinase. Am J Physiol Endocrinol Metab 2003,285,(4):E708-17.

[57] Kanda Y, Watanabe Y. Thrombin-induced glucose transport via Src-p38 MAPK pathway in vascular smooth muscle cells. Br J Pharmacol 2005,146,(1):60-7.

[58] Fiuza C, Bustin M, Talwar S, Tropea M, Gerstenberger E, Shelhamer JH, Suffredini AF. Inflammation-promoting activity of HMGB1 on human microvascular endothelial cells. Blood 2003,101,(7):2652-60.

[59] Plutzky J. Medicine. PPARs as therapeutic targets: reverse cardiology? Science 2003,302,(5644):406-7. 
[60] Vemuri VK, Janero DR, Makriyannis A. Pharmacotherapeutic targeting of the endocannabinoid signaling system: drugs for obesity and the metabolic syndrome. Physiol Behav 2008,93,(4-5):671-86. 


\section{Figure 1. General p38 MAP kinase signalling pathway schema related to}

stimulation by growth factors. The major components shown are the trio of members of the MAP kinase cascade being MAPKKK (MAPK kinase kinase), MAPKK (MAPK kinase) and MAPK MAP kinase. Various effectors at the level of the intracellular site of the receptors activate MAPKKK(s). The cascade through p38 MAP kinase leads to activation of cell process as described in the text. Relevant vasoactive agonists are the tyrosine kinase Platelet derived growth factor receptor (PDGFR), the serine/threonine kinase transforming growth factor $\beta$ (TGF $\beta R$ ) and the 7 transmembrane $G$ protein coupled angiotensin II (AII) and endothelin (ET) receptors.

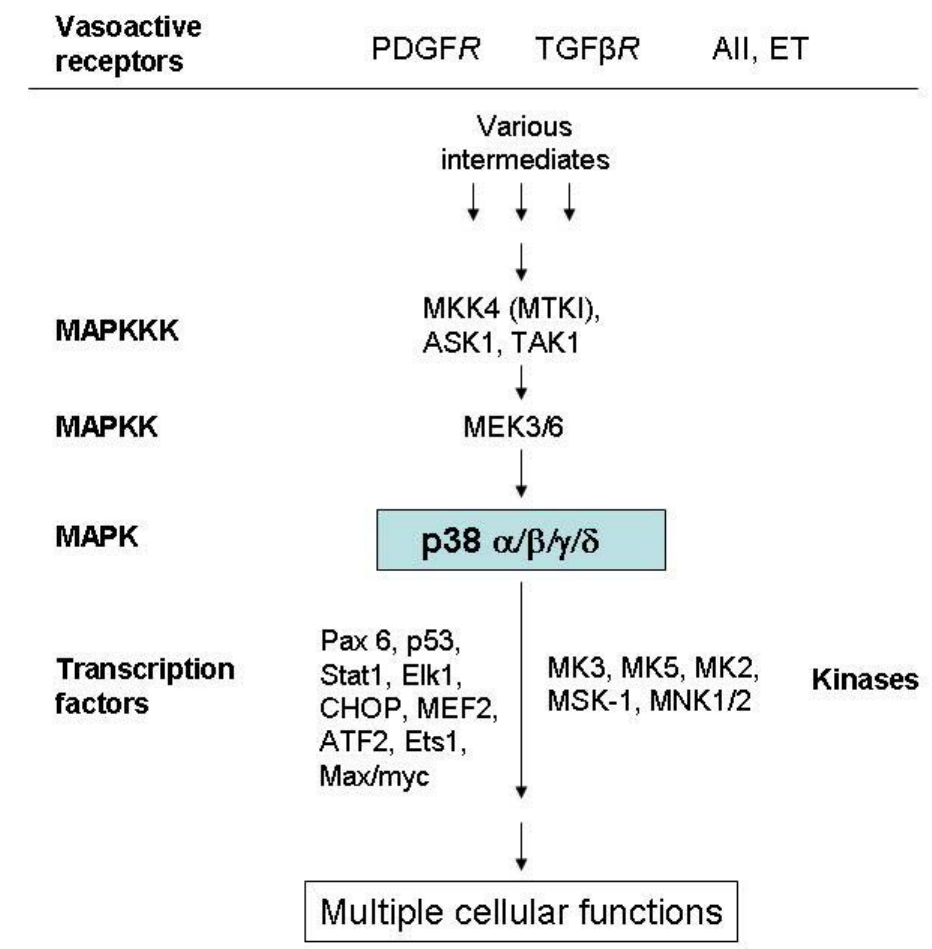


Figure 2. p38 MAP kinase and its potential activation pathways leading to GAG elongation, lipid retention and the development of atherosclerosis. Signalling pathways in vascular smooth muscle cells are depicted as cascades known to activate p38 MAP kinase and have downstream effects on cell proliferation and inflammation (PDGF), glucose uptake (thrombin, Thr), proteoglycan synthesis and GAG chain elongation (TGF $\beta$, Ang II) and extracellular matrix production (Ang II). The effect of hyperglycemia in diabetes on p38 MAP kinase and its signalling mediators to GAG elongation is not known.

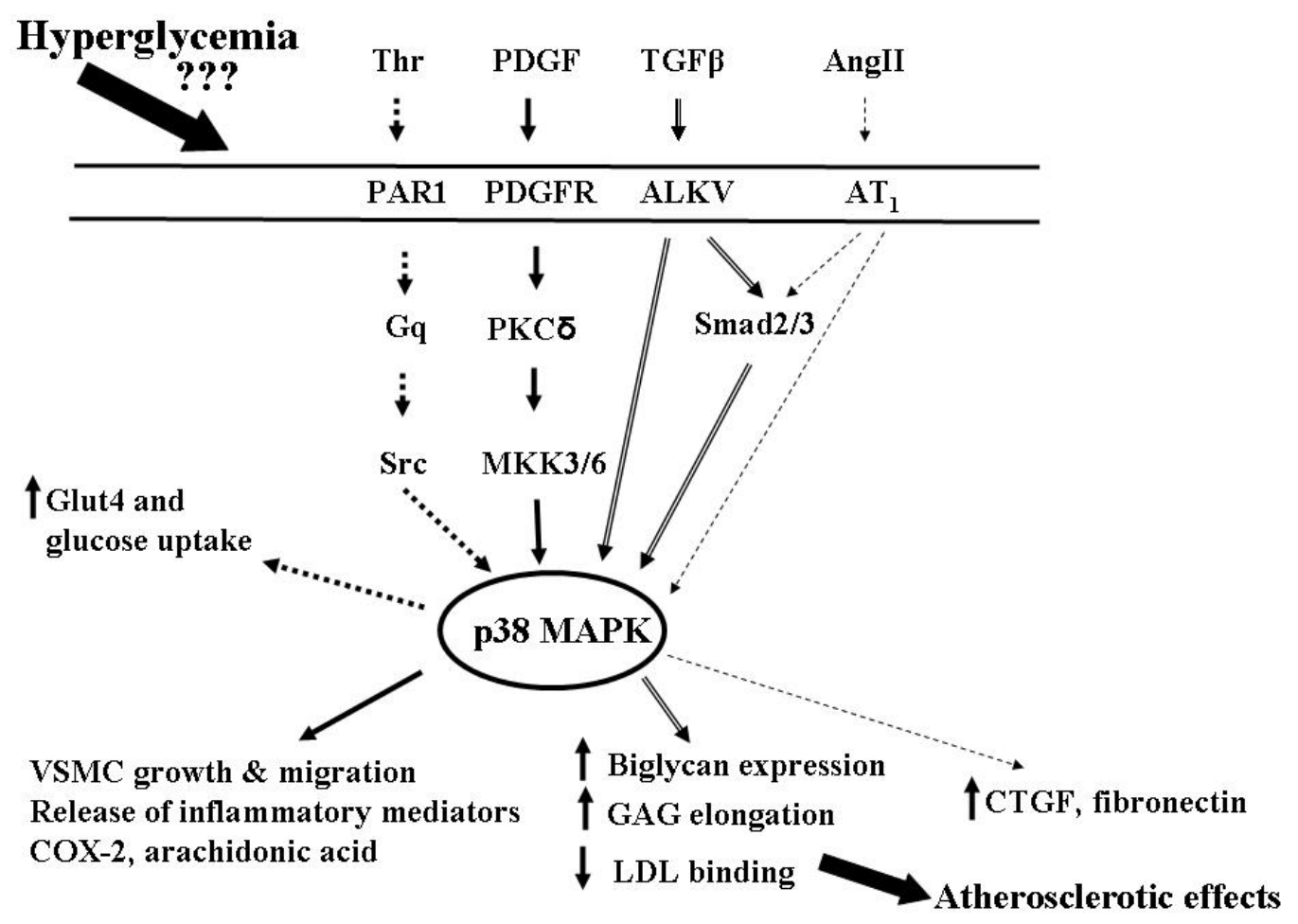

